\title{
Home and Parenting Resources Available to Siblings Depending on Their Birth Intention Status
}

\author{
Jennifer S. Barber \\ University of Michigan
}

\author{
Patricia L. East \\ University of California, San Diego
}

\begin{abstract}
This study examines the differential availability of family and parenting resources to children depending on their birth planning status. The National Longitudinal Survey of Youth data were analyzed, 3,134 mothers and their 5,890 children $(M=7.1$ years, range $=1$ month-14.8 years), of whom $63 \%$ were intended at conception, $27 \%$ were mistimed, and 10\% were unwanted. Fixed-effects models show that unwanted and mistimed children had fewer resources than intended siblings. Parents' emotional resources to older children decreased after the birth of a mistimed sibling. Findings suggest that cognitive and emotional resources are differentially available to children within a family depending on intention status and that unintended births lead to decreased parental resources for older children in the household.
\end{abstract}

It is well known that families differentially distribute available resources to different children within a family (Behrman, 1997; Foster, 2002). Indeed, the distribution of family resources to children is a complex and dynamic decision process involving a range of parental investment "currencies," such as parental time, attention, money, and even parental love and confidence in each child's future (Blake, 1987; Mayer, 1997). When analyzed within this human capital perspective, studies consistently reveal patterns in how resources are allocated across children (Behrman, Pollak, \& Taubman, 1995; Thomas, 1990). Even when considering families with limited income, parents tend to concentrate resources on some children and not on others (Pitt, Rosenzweig, \& Hassan, 1990). Research from a biosocial perspective also suggests that intrafamily resource allocation reflects parents' investment strategies to particular offspring (Draper \& Harpending, 1987). However, much of this research has focused on sibling inequities based on family structural factors, such as birth order (Conley, 2004), child gender (Behrman, Pollak, \& Taubman, 1986), the gender of one's siblings (Conley, 2000), and birth spacing between siblings (Rosenzweig, 1986). We focus instead on

This research was supported by Grant R01-HD39285 from NICHD (J.S.B.) and by Grants R01-HD043221 from NICHD and APR-006013 from the Office of Population Affairs (P.L.E.).

Correspondence concerning this article should be addressed to Jennifer S. Barber, Institute for Social Research, University of Michigan, 426 Thompson Street, Ann Arbor, MI 48106-1248. Electronic mail may be sent to jebarber@umich.edu (or) peast@ ucsd.edu. an ideational component of the family-mothers' evaluations of their pregnancies as intended, mistimed, or unwanted-and how it affects the distribution of family resources to the children resulting from these pregnancies, and the other children within a family.

Recent estimates indicate that as many as $35 \%$ of U.S. live births are unintended at the time of conception (Chandra, Martinez, Mosher, Abma, \& Jones, 2005). Children born as a result of an unintended birth encompass two groups of children: those who are reported as unwanted at conception and those characterized as "mistimed," or conceived earlier than parents would have preferred (Henshaw, 1998). For many U.S. parents, however, an intended child is followed by a child or children resulting from a mistimed or unwanted pregnancy. Within these families, how does birth intention status affect the distribution of family and parental resources? Do children whose births were unintended (unwanted or mistimed) have less access to family resources than their siblings whose births were intended? If yes, what is the extent of their disadvantage in terms of cognitive and emotional resources?

Surely these evaluations of pregnancies as intended or unintended are likely to have some association with the material and emotional investments parents make in the resulting children.

(c) 2009, Copyright the Author(s)

Journal Compilation $\odot$ 2009, Society for Research in Child Development, Inc. All rights reserved. 0009-3920/2009/8003-0022 
Parents might resent the time and attention that children from unwanted or mistimed conceptions demand, and they may be less likely to spend quality time with them (Barber, Axinn, \& Thornton, 1999). Similarly, unwanted or mistimed births may impose a financial burden on the family, and parents may resent an unintended child and differentially allocate available resources to favor their intended offspring. Additionally, parents may have less interest in a child born from an unintended conception, diminishing the likelihood of emotional or cognitive investments in the child (Axinn, Barber, \& Thornton, 1998).

Two studies have examined the relation between unintended childbearing and family resource allocation. One study, focusing on infants, found that mistimed and unwanted 1-year-olds had fewer home and parenting resources available to them than did children who were wanted at conception. However, when controlling for a host of family-level factors, many of these bivariate associations disappeared (Baydar, 1995). The second study similarly found that mothers' pre- and postpartum health behaviors favored intended children, but that most of the disparity was due to compositional differences between mothers with intended births versus mothers with unintended births (Joyce, Kaestner, \& Korenman, 2000a). In other words, when health behaviors were compared across multiple pregnancies within the same mother using sophisticated fixed-effects models, relatively few differences were found between unintended and intended births. Joyce and colleagues' innovative and provocative findings cast doubt on much of the prior research on unintended childbearing. The similarities between intended and unintended children within the same family led them to conclude that many or all of the negative consequences attributed to unintended childbearing are due to differences in the types of mothers who plan and fail to plan their births. In other words, unmeasured family-level factors may explain the difference between unintended and intended births. Alternatively, we propose that the consequences of an unintended birth "spill over," affecting all children within the family. This spill over would lead to the same observed similarity between intended and unintended siblings within the same family but would suggest a causal rather than spurious relation.

Indeed, we currently do not know how an unintended birth affects the other children in a family. It is likely that home and parental resources are impacted by an unintended birth, as suggested by the finite nature of home and family capital. Family expenditures are clearly not unlimited (Becker \& Thomes, 1986; Foster, 2002). Parents' time is often conceptualized as a finite resource that is carefully and purposively allotted among children, as well (e.g., Sandberg \& Hofferth, 2001). Several previous studies also show that the emotional resources available to children from their parents decline significantly, on average, after an additional birth (without attending to the intention status of that birth). For example, mothers' positive and affectionate interactions with the older child decrease and their punitive-controlling behaviors increase after the birth of a sibling (Baydar, Greek, \& Brooks-Gunn, 1997). These effects remain even when controlling for changes in families' financial resources that may precede the birth of an additional child. Five years after the birth of a sibling, the older child continues to experience significantly more harsh and punitive parenting (Baydar, Hyle, \& BrooksGunn, 1997). We build on these findings by exploring whether intention status amplifies differences in parental treatment.

Although some previous research has examined parenting resources in relation to unintended childbearing, those analyses were unable to separate the role of family socioeconomic status from the role of intention status. For example, Baydar (1995) found that characteristics of the family, such as income and marital status, in the wave after a child's birth explained much or all of the relationship between the child's intention status and the parenting resources available to him or her. Baydar (1995) suggests that mothers' expectations regarding income and marital status may affect her evaluation of a pregnancy as intended or unintended. We propose that actual changes in income and marital status as a consequence of an unintended birth may be related to reductions in the parenting resources available to children, as well.

We have three specific goals. First, we use fixedeffects models similar to Joyce et al. (2000a) and Joyce, Kaestner, and Korenman (2000b) to compare siblings within a family in terms of an underexplored and important influence on children's development-parenting resources available to children. Second, we directly test the spillover hypothesis with crosslag models that compare changes in parenting resources available to existing children after experiencing unintended and intended sibling births. Third, we use interviewer observations as more objective measures (than mothers' reports) of the home environment. We describe each of these goals in greater detail below. 


\section{Comparing Parenting Resources Available to Siblings Within a Family}

Family-level fixed-effects modeling is an important tool to determine whether the observed relations between unintended childbearing and child well-being are causal. These models compare one sibling with the "condition" of interest to another sibling without the condition (see, e.g., Geronimus and Korenman's, 1992, research on the consequences of teenage childbearing). Joyce et al. (2000a, 2000b) applied this type of fixed-effects sibling model to compare children born from unintended births and those born from intended births within the same family. They found similar maternal behavior and child outcomes among intended and unintended pregnancies within the same family. They interpret these findings as evidence that low cognitive skills are not actually a consequence of unintended childbearing-rather, that they result from family-level unobserved heterogeneity (Joyce et al., 2000a, 2000b).

We use similar fixed-effects (or within-mother) models to compare siblings, but we estimate these models for a new, and particularly important, potential consequence of unintended childbearing-cognitive and emotional parental resources available to children. We compare unintended children to their intended siblings. These fixed-effects models adjust or control for the unmeasured confounders that stem from shared family background. That is, comparing siblings who have the same mother and who are raised in the same family (and, notably, within the same socioeconomic standards) controls for the unobserved effects associated with family heterogeneity. This first step of our analysis allows us to determine whether there are differences among siblings within the same family, in terms of these important indicators of child development. Furthermore, we estimate multiple versions of these models to illustrate the extent to which shared family background explains the overall observed relation between intention status and parental resources.

\section{Changes in Parenting Resources After an Unintended Versus Intended Birth}

Our second step is to exploit longitudinal data on families to examine change in parental resources after an unintended child is born. Recent research suggests that parental resources decline after the birth of a sibling and that the birth can also affect children's cognitive and social development
(Baydar, Greek, et al., 1997; Baydar, Hyle, et al., 1997). We hypothesize that a mother's evaluation of a birth as unintended may exacerbate that decline in parenting resources. Thus, as an extension of this research, we propose that unintended siblings will affect the other children in a family. This is the spillover hypothesis described above.

The multiwave longitudinal data used in the current study allow us to compare the decrease in family resources after the birth of an unintended sibling to the decrease in family resources after the birth of an intended sibling. If family resources decline disproportionately with an unintended as opposed to an intended birth, then-in addition to whatever disadvantages may accrue to the unintended child by virtue of this birth status-relatively fewer resources would be available to allocate across all children. This is a direct test of the spillover hypothesis. Results supporting a spillover hypothesis would suggest a reinterpretation of Joyce et al.'s findings that unintended and intended siblings within the same family are similar in terms of maternal behaviors and child outcomes. Rather than null effects of unintended childbearing, we would interpret the effects of unintended childbearing to be broader than previously believed-accruing to more than the child born from the unintended pregnancy him or herself.

\section{Causal Issues in Research on Unintended Childbearing}

Without experimental data, it is difficult to determine whether the negative experiences of mothers and children associated with unintended births are actually caused by the unintended birth (Brown \& Eisenberg, 1995). Do the disadvantages reflect characteristics of the families most likely to have unintended births or the unintended birth itself? All families change after the birth of a child. At a minimum, the family has an additional member to feed, clothe, and shelter. If the associations between unintended childbearing and lower child wellbeing are mainly because families with unintended births are different from other families before the unintended birth, then this suggests a spurious relationship. However, if among otherwise similar families, those who have unintended births experience more negative changes than those who have intended births, a causal relationship between the unintended birth and child well-being is plausible.

It is impossible to completely rule out this unobserved heterogeneity hypothesis, and it is impossible to rule out the notion that families who expect negative changes are most likely to evaluate their 
pregnancies and births as unintended. However, we argue that many of the mechanisms-e.g., living arrangements and relationships, parents' education, and family financial resources-that could link unintended childbearing to child development are likely to apply equally to all children in a family, not just the child born from the unintended birth. Thus, we expect a family-level effect rather than a simple impact on parenting behavior with a particular child, or on his or her development. As Joyce et al. (2000a, 2000b) suggest, their results may not rule out a causal relation if the negative consequences of unintended childbearing are experienced by all of the children in a family.

Thus, our third step is to examine the change in parental resource availability using both mother reports of the home environment and ratings made by an objective observer who was unaware of children's intention status. Certainly it could be the case that mothers who evaluated their recent birth as unintended (either mistimed or unwanted) describe the home environment more negatively than mothers who evaluated their recent birth as intended, regardless of the true quality of the home environment. For example, this may be because mothers with recent unintended births may be experiencing depression or health problems, which influence their perceptions of the home environment they are providing (Barber et al., 1999; Brown \& Eisenberg, 1995). Analyses using an objective observer's ratings could corroborate results found using mother ratings.

Because unintended births occur disproportionately among less educated, low-income mothers who have many children (Chandra et al., 2005; Joyce et al., 2000a, 2000b), it is also important to control for these and other family background factors that could independently affect the level of family resources. We include an extensive set of measures at the family level. Because family resource allocation varies by birth order, gender, and the age of the child, these and other characteristics of the child are also included in all analyses. Finally, because resource allocation may vary over time and depend on the circumstances of that particular moment in time, we control for a host of time-varying characteristics of the assessment itself. In addition, in our models of the relation between the child's own intention status and parental resources available to him or her, the fixed-effects nature of the models incorporates a control for unobserved heterogeneity in families by comparing siblings within the same family. In our models of change in parental resources, we include a parallel measure of parental resources before the birth in our models of parental resources after the birth. Although this does not directly address omitted variable bias, it does allow us to look at the level of postbirth parental resources within levels of prebirth parental resources. This is an important advance over models that do not have a parallel control for prebirth resources. We further discuss the details of these models in the Analysis section.

\section{Method}

\section{Data}

We use data from multiple waves of the 1979 National Longitudinal Survey of Youth (NLSY79), initiated in 1979 for a nationally representative sample of 12,686 young men and women who were then 14 to 22 years of age. Data have been collected annually on these youth through 1994 and biennially since. In addition, beginning in 1986, information was collected biennially from the female sample about all children living in the household (NLSY-C). Thus, the NLSY79 combined with the NLSY-C is a rich source of information about the experiences of young women as they became mothers, and on the birth, childhood, and early adulthood of each of their children. We use these combined data through the 2004 survey wave. Because we focus on family change after the birth of a child, our sample includes only those women who experienced a live birth. This involved 29,456 assessments of 5,890 children born to 3,134 mothers, or 5,890 mother-child pairs. Births up to and including the year 2004 represent a cross-section of children born to women who were between 39 and 47 years of age in 2004. The NLSY website reports that these children represent approximately $90 \%$ of possible births that will occur to the cohorts of women born between 1957 and 1964 (http:// ftp:/ / www.nlsinfo.org/pub/usersvc/Child-YoungAdult/2004ChildYA-DataUsersGuide.pdf).

\section{Measures}

Intention status of birth. Our key independent variable is the intention status of the birth. Women who had recently given birth were asked: "Just before you became pregnant the (first, second, third, etc.) time, did you want to become pregnant when you did?" If they answered yes, the birth was classified as intended. If they answered "no," they were then asked, "Did you want a(nother) baby but not at that time, or did you want (none/no 
more) at all?" If they answered that they wanted another baby, their birth was classified as mistimed. If they answered that they wanted none/no more babies, their birth was classified as unwanted. Certainly, feelings about wanting or intending to have a child may change from conception to birth (Joyce et al., 2000b); thus, it should be noted that women were asked about their preconception birth intentions in the current study.

The coding of intention status of each birth was complicated by the fact that not all women were interviewed in every survey, and women answered questions about their pregnancies and births in reference to the period since the last interview. However, when we checked our coding against that of Joyce et al. (2000a, 2000b), who also used the NLSY for their analyses, we had identical coding for 95\% of cases in which our samples overlapped. For an additional $3 \%$, we had a code where they had missing data. Of the remaining $2 \%$ of cases, either we assigned a "mistimed" code and they assigned a code of "unwanted" or vice versa, but we were still in agreement that the pregnancy was unintended. Descriptive statistics for this and all other variables we used in the analyses are presented in Table 1. Just under two thirds of pregnancies were intended, $27 \%$ were mistimed, and $10 \%$ unwanted.

Parental resources. We examine two types of resources parents provide to their children: cognitive resources (learning materials and opportunities in the home) and emotional resources (positive mother-child interactions and warm/nurturing parenting). The Home Observation for Measurement of the Environment Inventory (HOME; Caldwell \& Bradley, 1984) was administered in the NLSY every 2 years from 1986 to 2004, and is based on mother reports and interviewer observations. The Home measures the quality of the child's developmental environment and is typically divided into two subscales: a cognitive stimulation score and an emotional resource scale. The cognitive stimulation score indexes the personal and material opportunities for skill development that are intended to enhance children's cognitive development. This scale includes such items as the number of children's books in the home, the frequency of a parent reading to the child, frequency of parents teaching the child new skills (counting, the alphabet), and the availability of age-appropriate learning materials. The emotional resource scale assesses the warmth and responsivity of the mother, the mother's parenting style, the time the family spends together, the time the father spends with the child, and the extent that parents promote the child's independence. The coding of both cognitive and emotional resources is gradated by children's age. For example, taking the child to a grocery store was coded as a cognitive resource up to age 3 , and taking the child to a museum was coded as a cognitive resource from ages 3 to 10 years. Similarly, emotional resources were indexed from birth to 3 years of age by whether the mother spoke to the child, and was later coded as whether the mother and child conversed with each other (from 3 to 15 years). Each HOME item was coded as present (1) or absent (0). Because the number of items at each developmental period varied, scores were normalized such that the standard score mean was 100 and the standard deviation was 15 . Because these scores are nationally normalized and standardized, we combine the HOME scores across the ages.

We also conducted analyses using a subset of the ratings used to compute the full HOME score- the interviewer's ratings. The full HOME score includes these interviewer ratings as well as mother observations. The interviewer observations include items used in both the cognitive and emotional subscales. For the cognitive subscale, interviewers observed four things-whether the play environment is safe (different questions for different age children), whether the home is dark or perceptually monotonous (e.g., closed drapes in daytime, poor lighting), whether the home is reasonably clean (e.g., trash in the home, dirty floors), and whether the home is minimally cluttered (e.g., rooms are cluttered with clothes, vacuum cleaner, etc.). For the emotional subscale, the interviewer observed mothers' direct interactions with their children, such as conversation, or spanking/slapping. There is no national norming available for the interviewer observations subset of the HOME score; thus, we use these items to form a simple index, which sums the dichotomous indicators (of yes or no) and divides them by the total possible score. Thus, this measure ranges from 0 to 1 . The HOME interviewer observations have acquired considerable validation as applied in a wide array of studies throughout the world (Bradley \& Corwyn, 2005) and shows patterns of relations with age, ethnicity and children's cognitive development at different age points that are in line with theoretical expectations (Bradley, Corwyn, McAdoo, \& Coll, 2001a, 2001b).

Unfortunately, in order to have enough cases for analysis, we must pool the different age groups, which effectively forces us to consider the HOME score as equivalent across age group. In fact, in our change models, the HOME score used as a control variable is not necessarily composed of the exact 
Table 1

Descriptive Statistics for Measures Used in Analyses ( $N=29,456$ Observations)

\begin{tabular}{|c|c|c|c|c|}
\hline & $M$ & $S D$ & Min. & Max. \\
\hline \multicolumn{5}{|l|}{ Measures of parental resources } \\
\hline Total HOME score & 97.12 & 15.99 & 4.00 & 133.20 \\
\hline Cognitive support subscore ${ }^{a}$ & 97.40 & 15.97 & 5.70 & 148.20 \\
\hline Emotional support subscore ${ }^{\mathrm{b}}$ & 97.83 & 15.93 & 6.50 & 133.60 \\
\hline Interviewer rating of home safety and appearance & .82 & .25 & 0 & 1.00 \\
\hline \multicolumn{5}{|l|}{ Measures of intention status } \\
\hline \multicolumn{5}{|l|}{ Child's birth intention status } \\
\hline Unwanted & .10 & & 0 & 1 \\
\hline Mistimed & .27 & & 0 & 1 \\
\hline Unintended (unwanted or mistimed) & .37 & & 0 & 1 \\
\hline Intended & .63 & & 0 & 1 \\
\hline \multicolumn{5}{|l|}{ Younger sibling's birth intention status ${ }^{c}$} \\
\hline Unwanted & .10 & & 0 & 1 \\
\hline Mistimed & .27 & & 0 & 1 \\
\hline Unintended (unwanted or mistimed) & .37 & & 0 & 1 \\
\hline Intended & .63 & & 0 & 1 \\
\hline \multicolumn{5}{|l|}{ Mother-/family-level measures } \\
\hline Family income (in 1979 \$) & $\$ 22,476$ & $\$ 37,107$ & 0 & $\$ 648,741$ \\
\hline Home ownership & .49 & & 0 & 1 \\
\hline Mother lives with spouse/partner & .50 & & 0 & 1 \\
\hline Mother lives with parents & .07 & & 0 & 1 \\
\hline Mother's total number of children & 2.49 & 1.17 & 0 & 9 \\
\hline Mother's education & 12.89 & 2.31 & 0 & 20 \\
\hline Mother's AFQT score & 37.78 & 27.54 & 1.00 & 99.00 \\
\hline \multicolumn{5}{|l|}{ Race } \\
\hline Caucasian & .49 & & 0 & 1 \\
\hline Latino & .21 & & 0 & 1 \\
\hline African American & .30 & & 0 & 1 \\
\hline \multicolumn{5}{|l|}{ Region of residence $^{c}$} \\
\hline Northeast & .15 & & 0 & 1 \\
\hline North central & .26 & & 0 & 1 \\
\hline West & .21 & & 0 & 1 \\
\hline South & .38 & & 0 & 1 \\
\hline \multicolumn{5}{|l|}{ Child-level measures } \\
\hline Mother's age at child's birth & 26.09 & 4.69 & 15 & 42 \\
\hline Child low birth weight & .08 & & 0 & 1 \\
\hline Child's birth order & 2.01 & 1.11 & 1 & 10 \\
\hline Child is female & .49 & & 0 & 1 \\
\hline Total number of assessments & 5.82 & 1.36 & 1 & 8 \\
\hline \multicolumn{5}{|l|}{ Assessment-level measures } \\
\hline Age at assessment (in months) & 85.23 & 47.50 & 0 & 178 \\
\hline Order of assessment & 3.40 & 1.83 & 1 & 8 \\
\hline Wave & 5.22 & 2.55 & 1 & 10 \\
\hline
\end{tabular}

Note. The 29,456 observations used for Table 1 correspond to the analyses in Table 2. Descriptive statistics for the 2,200 observations used in Table 5 are very similar. HOME = Home Observation for Measurement of the Environment; AFQT = Armed Forces Qualifying Test.

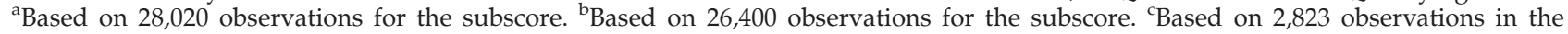
sibling change models.

same questions as the HOME score used as the dependent variable. This is, however, an improvement over existing research that controls for a completely different assessment rather than a nearly parallel assessment. For example, Baydar and colleagues Baydar, Greek, et al., 1998; Bayder, Hyle, et al., 1997 control for the Motor and Social Development score in models of PIAT and PPVT scores. Thus, our models are not strictly "change" models, but rather models of the HOME score regressed on an earlier measure of the quality of the home environment, plus other controls. 
Controls. Our models also include numerous control variables at the mother/family, focal child, and assessment levels that might be linked with intention status as well as family resource availability.

First, we include multiple characteristics of the mother or her family, which apply to all of her children. Family income is a measure of total family income from all sources, ascertained from the mother for the year prior to the interview, and presented in $\$ 1,000$ units. In other words, a family with an income of $\$ 20,000$ is coded as 20 , and a variation of one unit is equivalent to a $\$ 1,000$ difference. All income information is converted to 1979 dollars based on the consumer price index. For example, a family that reported $\$ 50,000$ of income from all sources in 1982 is coded $66.5(50 \times 1.33)$. Home ownership is a dichotomous measure, coded 1 if the mother owned her home. If the mother was living with her parents, she was coded 0 on home ownership. An indicator of whether the mother was living with a spouse or partner (not necessarily the father of the sample child) is coded 1 (living with a partner) or 0 (not living with a partner). (We also reran all models with a measure of whether the mother lived with the child's father. The results were quite similar.) By searching the relationship codes in the mother's household listing, we were also able to determine if the mother was living with her parents (coded as 1). Mother's education was coded as her highest grade of school completed, which ranged from 0 to 20 years. Because gauging the allocation of resources requires assessing the number of individuals involved in the distribution (McGarry \& Schoeni, 1995), we included family size- or the number of children who lived in the household-in all analyses. As a measure of mothers' cognitive skills, we used her percentile score on the Armed Forces Qualifying Test (AFQT), which was completed by all NLSY79 women in 1980 . These percentile scores are divided by 10 so that a mother who scored 50 was coded as 5 , and a oneunit difference between mothers for this variable is equivalent to 10 percentile points. In addition, we include her race/ethnicity, coded as non-Hispanic White (the reference category), Latina, or African American; and her region of residence in the United States at the time of the assessment, coded as Northeast, North Central, West, and South (the reference category). In the equations that follow, we refer to these measures as mother/family-level controls, or family background controls when the mother/family level is not explicitly represented in the model.
Second, we also included several characteristics of the focal child: the mother's age at the focal child's birth, which ranged from 15 to 40; a dichotomous indicator of low birth weight for the focal child (coded as 1 for a birth weight of $5.5 \mathrm{lb}$ or less); the child's gender ( $1=$ girl, $0=$ boy); and the child's birth order (coded as 1 through 10, with 1 indicating first born). Total number of assessments indicates the total number of observations the child contributed to each analysis and controls for repeated measurement and longitudinal participation. In models assessing change after the birth of a younger sibling, we also included a dichotomous indicator of whether the younger sibling was the same sex as the older sibling (coded as 1). These are the child-level controls.

Finally, several variables controlled for characteristics of the assessment. The focal child's age at assessment is coded in months; this also controls for the age difference between siblings. Temporal order, which refers to the sequence in which an individual observation took place among all observations of a child, controls for effects of repeated measurement of the home environment and continued participation in the longitudinal study. Finally, wave is an index of the year the assessment took place-with codes ranging from 1 (1986) to 8 (2002) - and controls for changes over time in the home environment experienced by all participating families. We refer to these measures as assessmentlevel controls, because even when referencing the same child, they vary by the specific assessment.

\section{Analysis}

Children's birth intention status and resource availability. We used two- and three-level models to assess the correlation between the intention status of a child's birth and his/her HOME score. There are multiple assessments from some children, and a single assessment from some children; the range is from 1 to 8 assessments per child (see Table 1). The ordinary least squares (OLS) models shown in Tables 2-5 use all of these assessments as dependent variables; the models ignore whether the score comes from the same child. This is a simple OLS regression model, ignoring the nonindependence of observations due to clustering of observations within individuals and within families. This model is mainly for comparison to the two-level and three-level models.

The two-level models statistically account for the correlation between scores from the same child. In other words, the model does not assume that each 
Table 2

One-, Two-, and Three-Level Models of the Relation Between Child's Birth Intention Status and Total HOME Score

\begin{tabular}{|c|c|c|c|c|c|c|}
\hline & \multicolumn{2}{|c|}{ OLS } & \multicolumn{2}{|c|}{ Two level } & \multicolumn{2}{|c|}{ Three level } \\
\hline & 1 & 2 & 3 & 4 & 5 & 6 \\
\hline \multicolumn{7}{|l|}{ Child's birth intention status $^{\mathrm{a}}$} \\
\hline $\begin{array}{l}\text { Unintended (unwanted } \\
\text { or mistimed) }\end{array}$ & $-1.29^{* * *}(.18)$ & & $-1.62^{* * *}(.27)$ & & $-.49^{* *}(.20)$ & \\
\hline Unwanted & & $-1.96^{* * *}(.29)$ & & $-2.42^{* * *}(.45)$ & & $-.95^{* *}(.34)$ \\
\hline Mistimed & & $-1.09^{* * *}(.19)$ & & $-1.37^{* * *}(.29)$ & & $-.37^{*}(.21)$ \\
\hline \multicolumn{7}{|l|}{ Mother-/family-level measures } \\
\hline $\begin{array}{l}\text { Family income } \\
\text { (in } \$ 1,000 \text { s of } 1979 \$ \text { ) }\end{array}$ & $.03^{* * *}(.002)$ & $.03^{* * *}(.002)$ & $.01^{* * *}(.002)$ & $.01^{* * *}(.002)$ & $.01^{* * *}(.002)$ & $.01^{* * *}(.002)$ \\
\hline Home ownership & $3.17^{* * *}(.18)$ & $3.16^{* * *}(.18)$ & $1.67^{* * *}(.18)$ & $1.67^{* * *}(.18)$ & $1.26^{* * *}(.19)$ & $1.26^{* * *}(.19)$ \\
\hline $\begin{array}{l}\text { Mother lives with } \\
\text { spouse/partner }\end{array}$ & $4.79^{* * *}(.20)$ & $4.78^{* * *}(.20)$ & $3.26^{* * *}(.19)$ & $3.26^{* * *}(.19)$ & $2.91^{* * *}(.19)$ & $2.90^{* * *}(.19)$ \\
\hline Mother lives with parents & $-.22(.33)$ & $-.21(.33)$ & $-.06(.34)$ & $-.06(.34)$ & $.08(.34)$ & $.08(.34)$ \\
\hline $\begin{array}{l}\text { Mother's total number } \\
\text { of children }\end{array}$ & $-.89^{* * *}(.09)$ & $-.96^{* * *}(.05)$ & $-.56^{* * *}(.10)$ & $-.56^{* * *}(.10)$ & $-.56^{* * *}(.11)$ & $-.56^{* * *}(.11)$ \\
\hline Mother's education & $.96^{* * *}(.05)$ & $.96^{* * *}(.05)$ & $.88^{* * *}(.07)$ & $.88^{* * *}(.07)$ & $.68^{* * *}(.08)$ & $.68^{* * *}(.08)$ \\
\hline Mother's AFQT score & $.70^{* * *}(.04)$ & $.70^{* * *}(.04)$ & $.85^{* * *}(.07)$ & $.85^{* * *}(.07)$ & $1.01^{* * *}(.08)$ & $1.01^{* * *}(.08)$ \\
\hline \multicolumn{7}{|l|}{ Race $^{\mathrm{b}}$} \\
\hline Latino & $-2.62^{* * *}(.24)$ & $-2.61^{* * *}(.24)$ & $-2.84^{* * *}(.37)$ & $-2.83^{* * *}(.37)$ & $-2.88^{* * *}(.48)$ & $-2.87^{* * *}(.48)$ \\
\hline African American & $-6.24^{* * *}(.24)$ & $-6.20^{* * *}(.24)$ & $-6.73^{* * *}(.36)$ & $-6.68^{* * *}(.36)$ & $-6.64^{* * *}(.45)$ & $-6.61^{* * *}(.45)$ \\
\hline \multicolumn{7}{|l|}{ Region of residence $^{c}$} \\
\hline Northeast & $1.94^{* * *}(.25)$ & $1.93^{* * *}(.25)$ & $1.60^{* * *}(.35)$ & $1.59^{* * *}(.35)$ & $1.49^{* * *}(.42)$ & $1.48^{* * *}(.42)$ \\
\hline North central & $.96^{* * *}(.21)$ & $.96^{* * *}(.21)$ & $.92 * *(.30)$ & $.92 * *(.30)$ & $.86^{* *}(.37)$ & $.86^{* *}(.37)$ \\
\hline West & $.48^{*}(.23)$ & $.48^{*}(.23)$ & $.60^{*}(.34)$ & $.60^{*}(.34)$ & $.83^{*}(.40)$ & $.83^{*}(.40)$ \\
\hline \multicolumn{7}{|l|}{ Child-level measures } \\
\hline $\begin{array}{l}\text { Mother's age at focal } \\
\text { child's birth }\end{array}$ & $.07^{*}(.04)$ & $.07^{*}(.04)$ & $.15^{* *}(.06)$ & $.15^{\star *}(.06)$ & $.10^{\dagger}(.07)$ & $.10^{\dagger}(.07)$ \\
\hline Child low birth weight & $-1.14^{* * *}(.30)$ & $-1.12^{* * *}(.30)$ & $-1.31^{* *}(.45)$ & $-1.28^{* *}(.45)$ & $-.58^{*}(.35)$ & $-.57^{*}(.35)$ \\
\hline Child's birth order & $-1.41^{* * *}(.10)$ & $-1.39^{* * *}(.10)$ & $-1.70^{* * *}(.15)$ & $-1.66^{* * *}(.15)$ & $-1.35^{* * *}(.12)$ & $-1.34^{* * *}(.12)$ \\
\hline Child is female & $1.86^{* * *}(.16)$ & $1.86^{* * *}(.16)$ & $1.88^{* * *}(.25)$ & $1.88^{* * *}(.25)$ & $1.54^{* * *}(.17)$ & $1.54^{* * *}(.17)$ \\
\hline Total number of assessments & $-.42^{* * *}(.08)$ & $-.42^{* * *}(.08)$ & $-.32 * *(.10)$ & $-.31^{* *}(.10)$ & $-.36^{* * *}(.10)$ & $-.35^{* * *}(.10)$ \\
\hline \multicolumn{7}{|l|}{ Assessment-level measures } \\
\hline Age at assessment & $.02^{* * *}(.01)$ & $.02 *(.01)$ & $.02^{* * *}(.01)$ & $.02^{* * *}(.01)$ & $.02^{* *}(.01)$ & $.02^{* *}(.01)$ \\
\hline Order of assessment & $.34^{*}(.15)$ & $.33^{*}(.15)$ & $.32 *(.18)$ & $.31^{*}(.18)$ & $.27^{*}(.16)$ & $.26^{*}(.16)$ \\
\hline Wave & $-.33^{* * *}(.09)$ & $-.33^{* * *}(.09)$ & $-.50^{* * *}(.13)$ & $-.50^{* * *}(.13)$ & $-.43^{* *}(.15)$ & $-.43^{* *}(.15)$ \\
\hline$N$ & 5,890 & 5,890 & 5,890 & 5,890 & 5,890 & 5,890 \\
\hline Observations & 29,456 & 29,456 & 29,456 & 29,456 & 29,456 & 29,456 \\
\hline Fit statistic ${ }^{\mathrm{d}}$ & .28 & .28 & $233,055.2$ & $233,060.4$ & $230,813.8$ & $230,811.2$ \\
\hline
\end{tabular}

Notes. Two-level models account for the correlation between multiple observations from the same child. Three-level models account for the correlation between multiple observations from the same child and multiple children with the same mother. Figures in parentheses are standard errors. HOME $=$ Home Observation for Measurement of the Environment; AFQT = Armed Forces Qualifying Test. ${ }^{a}$ Reference group is intended. ${ }^{b}$ Reference group is Caucasian. ${ }^{c}$ Reference group is South. ${ }^{\mathrm{d}}$ Fit statistic is $R^{2}$ (adjusted) for ordinary least squares (OLS) models and $-2 *$ residual log-likelihood for multilevel models.

${ }^{\dagger} p<.10 .{ }^{*} p<.05 .{ }^{* *} p<.01 .{ }^{* * *} p<.001$.

score is independent of each other score; rather, it assumes that multiple scores from the same child will be correlated (even though they were taken at different time points). This model is similar to the "cross-section OLS" models estimated by Joyce et al. (2000a, 2000b), except that Joyce et al. chose the first assessment (or the last assessment), rather than using all assessments for each child, and thus they did not need to account for the correlation within individuals. This model can be represented as follows, for observation $t$ for individual $i$ :

Level 1 model (assessment level)

$$
y_{t i}=\pi_{0 i}+\sum \pi_{1 i} \times \text { assessment-level controls }+e_{t i}
$$


Table 3

One-, Two-, and Three-Level Models of the Relation Between Child's Birth Intention Status and Emotional Support Subscore

\begin{tabular}{|c|c|c|c|c|c|c|}
\hline & \multicolumn{2}{|c|}{ OLS } & \multicolumn{2}{|c|}{ Two level } & \multicolumn{2}{|c|}{ Three level } \\
\hline & 1 & 2 & 3 & 4 & 5 & 6 \\
\hline \multicolumn{7}{|l|}{ 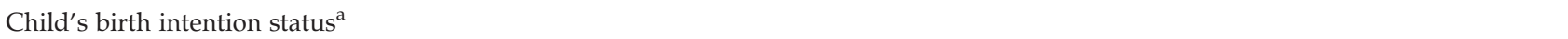 } \\
\hline $\begin{array}{l}\text { Unintended (unwanted } \\
\text { or mistimed) }\end{array}$ & $-1.35^{* * *}(.20)$ & & $-1.49^{* * *}(.27)$ & & $-.77^{* * *}(.23)$ & \\
\hline Unwanted & & $-2.01^{* * *}(.44)$ & & $-2.01^{* * *}(.44)$ & & $-1.15^{* *}(.39)$ \\
\hline Mistimed & & $-1.33^{* * *}(.29)$ & & $-1.33^{* * *}(.29)$ & & $-.67^{* *}(.24)$ \\
\hline \multicolumn{7}{|l|}{ Mother-/family-level measures } \\
\hline $\begin{array}{l}\text { Family income } \\
\text { (in } \$ 1,000 \text { s of } 1979 \$ \text { ) }\end{array}$ & $.02^{* * *}(.003)$ & $.01^{* * *}(.003)$ & $.01^{* * *}(.003)$ & $.01^{* * *}(.003)$ & $.01^{* * *}(.003)$ & $.01^{* * *}(.003)$ \\
\hline Home ownership & $2.70^{* * *}(.20)$ & $1.92^{* * *}(.21)$ & $1.92^{* * *}(.21)$ & $1.92^{* * *}(.21)$ & $1.55^{* * *}(.22)$ & $1.55^{* * *}(.22)$ \\
\hline $\begin{array}{l}\text { Mother lives with } \\
\text { spouse/partner }\end{array}$ & $6.06^{* * *}(.22)$ & $4.81^{* * *}(.22)$ & $4.82^{* * *}(.22)$ & $4.81^{* * *}(.22)$ & $4.36^{* * *}(.23)$ & $4.36^{* * *}(.23)$ \\
\hline Mother lives with parents & $-.80^{*}(.37)$ & $-.93^{* *}(.39)$ & $-.93^{* *}(.39)$ & $-.93^{* *}(.39)$ & $-.83^{*}(.40)$ & $-.83^{*}(.40)$ \\
\hline $\begin{array}{l}\text { Mother's total number } \\
\text { of children }\end{array}$ & $-.44^{* * *}(.10)$ & $-.34^{* *}(.12)$ & $-.34^{* *}(.12)$ & $-.34^{* *}(.12)$ & $-.36^{* *}(.12)$ & $-.36^{* *}(.12)$ \\
\hline Mother's education & $.35^{* * *}(.05)$ & $.31^{* * *}(.07)$ & $.31^{* * *}(.07)$ & $.31^{* * *}(.07)$ & $.21^{* *}(.08)$ & $.20^{* *}(.08)$ \\
\hline Mother's AFQT score & $.44^{* * *}(.05)$ & $.53^{* * *}(.07)$ & $.53^{* * *}(.07)$ & $.53^{* * *}(.07)$ & $.64^{* * *}(.08)$ & $.64^{* * *}(.08)$ \\
\hline \multicolumn{7}{|l|}{$\operatorname{Race}^{\mathrm{b}}$} \\
\hline Latino & $-.31(.27)$ & $-.46(.37)$ & $-.46(.37)$ & $-.46(.37)$ & $-.66^{\dagger}(.46)$ & $-.66^{\dagger}(.46)$ \\
\hline African American & $-6.12^{* * *}(.27)$ & $-6.47^{* * *}(.36)$ & $-6.51^{* * *}(.36)$ & $-6.47^{* * *}(.36)$ & $-6.73^{* * *}(.44)$ & $-6.70^{* * *}(.44)$ \\
\hline \multicolumn{7}{|l|}{ Region of residence ${ }^{c}$} \\
\hline Northeast & $2.05^{* * *}(.28)$ & $1.92^{* * *}(.36)$ & $1.92^{* * *}(.36)$ & $1.92^{* * *}(.36)$ & $1.88^{* * *}(.43)$ & $1.87^{* * *}(.43)$ \\
\hline North central & $1.19^{* * *}(.23)$ & $1.02^{* * *}(.31)$ & $1.02^{* * *}(.31)$ & $1.02^{* * *}(.31)$ & $.84^{*}(.37)$ & $.84^{*}(.37)$ \\
\hline West & $1.40^{* * *}(.26)$ & $1.41^{* * *}(.34)$ & $1.41^{* * *}(.34)$ & $1.41^{* *}(.34)$ & $1.51^{* * *}(.41)$ & $1.51^{* * *}(.41)$ \\
\hline \multicolumn{7}{|l|}{ Child-level measures } \\
\hline $\begin{array}{l}\text { Mother's age at focal } \\
\text { child's birth }\end{array}$ & $-.03(.04)$ & $.01(.06)$ & $.01(.06)$ & $.01(.06)$ & $-.02(.07)$ & $-.02(.07)$ \\
\hline Child low birth weight & $-1.12^{* * *}(.33)$ & $-1.20^{* *}(.44)$ & $-1.22^{* *}(.44)$ & $-1.20^{* *}(.44)$ & $-.29(.39)$ & $-.28(.39)$ \\
\hline Child's birth order & $-.96^{* * *}(.12)$ & $-1.02^{* * *}(.15)$ & $-1.04^{* * *}(.15)$ & $-1.02^{* * *}(.15)$ & $-.88^{* * *}(.14)$ & $-.86^{* * *}(.14)$ \\
\hline Child is female & $.99^{* * *}(.18)$ & $1.00^{* * *}(.24)$ & $1.00^{* * *}(.24)$ & $1.00^{* * *}(.24)$ & $.82^{* * *}(.20)$ & $.82^{* * *}(.20)$ \\
\hline Total number of assessments & $-.19 *(.09)$ & $-.20^{*}(.10)$ & $-.20 *(.10)$ & $-.20 *(.10)$ & $-.24^{* *}(.10)$ & $-.24^{* *}(.10)$ \\
\hline \multicolumn{7}{|l|}{ Assessment-level measures } \\
\hline Age at assessment & $.01^{*}(.01)$ & $.01 *(.01)$ & $.01 *(.01)$ & $.01 *(.01)$ & $.01 *(.01)$ & $.01 *(.01)$ \\
\hline Order of assessment & $.09(.15)$ & $.08(.17)$ & $.08(.17)$ & $.08(.17)$ & $.05(.16)$ & $.05(.16)$ \\
\hline Wave & $.23^{* *}(.10)$ & $.07(.12)$ & $.07(.12)$ & $.07(.12)$ & $.01(.15)$ & $.01(.15)$ \\
\hline$N$ & 5,819 & 5,819 & 5,819 & 5,819 & 5,819 & 5,819 \\
\hline Observations & 26,400 & 26,400 & 26,400 & 26,400 & 26,400 & 26,400 \\
\hline Fit statistic ${ }^{\mathrm{d}}$ & .19 & .19 & $214,136.2$ & $214,133.7$ & $212,817.5$ & $212,816.0$ \\
\hline
\end{tabular}

Notes. Two-level models account for the correlation between multiple observations from the same child. Three-level models account for the correlation between multiple observations from the same child and multiple children with the same mother. Figures in parentheses are standard errors. AFQT $=$ Armed Forces Qualifying Test.

${ }^{a}$ Reference group is intended. ${ }^{b}$ Reference group is Caucasian. ${ }^{c}$ Reference group is South. ${ }^{\mathrm{d}}$ Fit statistic is $R^{2}$ (adjusted) for ordinary least squares (OLS) models and $-2 *$ residual log-likelihood for multilevel models.

${ }^{\dagger} p<.10 .{ }^{*} p<.05 .{ }^{* *} p<.01 .{ }^{* * *} p<.001$.

where $y_{t i}$ is the score at time $t$ for child $i, \pi_{0 \mathrm{i}}$ is individual $i$ 's expected score when all assessment-level controls are set to zero (individual $i$ 's expected baseline score), $\Sigma \pi_{1 \mathrm{i}}$ is vector of slopes for assessment-level controls for individual $i$ 's score, and $e_{t i}$ is the error for the $i$ th individual at time $t$. Note that we use the $\Sigma$ symbol to avoid cumbersome notation when we are dealing with a vector of control variables. This shorthand indicates that $\pi_{1 i}$ represents a vector of coefficients associated with a vector of variables (assessment-level controls, which include age at assessment, temporal order, and survey wave). We use a similar shorthand when referring to child-level controls and mother/family-level controls. 
Table 4

One-, Two-, and Three-Level Models of the Relation between Child's Birth Intention Status and Cognitive Support Subscore

\begin{tabular}{|c|c|c|c|c|c|c|}
\hline & \multicolumn{2}{|c|}{ OLS } & \multicolumn{2}{|c|}{ Two level } & \multicolumn{2}{|c|}{ Three level } \\
\hline & 1 & 2 & 3 & 4 & 5 & 6 \\
\hline \multicolumn{7}{|l|}{ Child's birth intention status $^{a}$} \\
\hline $\begin{array}{l}\text { Unintended (unwanted } \\
\text { or mistimed) }\end{array}$ & $-1.01^{* * *}(.19)$ & & $-1.27^{* * *}(.28)$ & & $-.32^{\dagger}(.21)$ & \\
\hline Unwanted & & $-1.70^{* * *}(.31)$ & & $-2.03^{* * *}(.47)$ & & $-.68^{*}(.36)$ \\
\hline Mistimed & & $-.80^{* * *}(.20)$ & & $-1.04^{* * *}(.30)$ & & $-.23(.22)$ \\
\hline \multicolumn{7}{|l|}{ Mother-/family-level measures } \\
\hline $\begin{array}{l}\text { Family income } \\
\text { (in } \$ 1,000 \text { s of } 1979 \$ \text { ) }\end{array}$ & $.02^{* * *}(.002)$ & $.02^{* * *}(.002)$ & $.01^{* * *}(.002)$ & $.01^{* * *}(.002)$ & $.01^{* * *}(.002)$ & $.01^{* * *}(.002)$ \\
\hline Home ownership & $2.64^{* * *}(.19)$ & $2.63^{* * *}(.19)$ & $1.40^{* * *}(.20)$ & $1.40^{* * *}(.20)$ & $.97^{* * *}(.20)$ & $.96^{* * *}(.20)$ \\
\hline $\begin{array}{l}\text { Mother lives with } \\
\text { spouse/partner }\end{array}$ & $1.99^{* * *}(.21)$ & $1.97^{* * *}(.21)$ & $1.19^{* * *}(.20)$ & $1.18^{* * *}(.20)$ & $.93^{* * *}(.20)$ & $.93^{* * *}(.20)$ \\
\hline Mother lives with parents & $.46^{\dagger}(.35)$ & $.47^{\dagger}(.35)$ & $.73 *(.36)$ & $.73^{*}(.36)$ & $.84^{*}(.37)$ & $.84^{*}(.37)$ \\
\hline $\begin{array}{l}\text { Mother's total number } \\
\text { of children }\end{array}$ & $-1.04^{* * *}(.10)$ & $-1.04^{* * *}(.10)$ & $-.69^{* * *}(.11)$ & $-.69^{* * *}(.11)$ & $-.64^{* * *}(.11)$ & $-.64^{* * *}(.11)$ \\
\hline Mother's education & $1.19^{* * *}(.05)$ & $1.19^{* * *}(.05)$ & $1.15^{* * *}(.07)$ & $1.14^{* * *}(.07)$ & $.97^{* * *}(.09)$ & $.97^{* * *}(.09)$ \\
\hline Mother's AFQT score & $.70^{* * *}(.05)$ & $.69^{* * *}(.05)$ & $.80^{* * *}(.07)$ & $.80^{* * *}(.07)$ & $.21^{* *}(.08)$ & $.93^{* * *}(.09)$ \\
\hline \multicolumn{7}{|l|}{ Race $^{b}$} \\
\hline Latino & $-3.69^{* * *}(.26)$ & $-3.68^{* * *}(.26)$ & $-3.86^{* * *}(.39)$ & $-3.85^{* * *}(.39)$ & $-3.75^{* *}(.49)$ & $-3.75^{* * *}(.49)$ \\
\hline African American & $-4.50^{* * *}(.26)$ & $-4.46^{* * *}(.26)$ & $-4.85^{* * *}(.38)$ & $-4.80^{* * *}(.38)$ & $-4.52^{* * *}(.47)$ & $-4.49^{* * *}(.47)$ \\
\hline \multicolumn{7}{|l|}{ Region of residence $^{c}$} \\
\hline Northeast & $1.26^{* * *}(.26)$ & $1.25^{* * *}(.26)$ & $.87^{*}(.37)$ & $.85^{*}(.37)$ & $.80 *(.44)$ & $.80 *(.44)$ \\
\hline North central & $.42 *(.22)$ & $.42 *(.22)$ & $.46^{\dagger}(.32)$ & $.45^{\dagger}(.32)$ & $.49^{\dagger}(.39)$ & $.49^{\dagger}(.39)$ \\
\hline West & $-.20(.25)$ & $-.20(.25)$ & $-.04(.35)$ & $-.03(.35)$ & $.29(.42)$ & $.29(.42)$ \\
\hline \multicolumn{7}{|l|}{ Child-level measures } \\
\hline $\begin{array}{l}\text { Mother's age at focal } \\
\text { child's birth }\end{array}$ & $.13^{* * *}(.04)$ & $.13^{* * *}(.04)$ & $.22^{* * *}(.06)$ & $.22^{* * *}(.06)$ & $.21^{* *}(.08)$ & $.21^{* *}(.08)$ \\
\hline Child low birth weight & $-.62^{*}(.31)$ & $-.59 *(.31)$ & $-.86^{*}(.47)$ & $-.83^{*}(.47)$ & $-.89^{* *}(.37)$ & $-.88^{* *}(.37)$ \\
\hline Child's birth order & $-1.35^{* * *}(.11)$ & $-1.32^{* * *}(.11)$ & $-1.67^{* * *}(.15)$ & $-1.64^{* * *}(.15)$ & $-1.42^{* * *}(.13)$ & $-1.41^{* * *}(.13)$ \\
\hline Child is female & $1.99^{* * *}(.17)$ & $1.98^{* * *}(.17)$ & $1.95^{* * *}(.25)$ & $1.95^{* * *}(.25)$ & $1.63^{* * *}(.18)$ & $1.63^{* * *}(.18)$ \\
\hline $\begin{array}{l}\text { Total number of } \\
\text { assessments }\end{array}$ & $-.33^{* * *}(.08)$ & $-.32^{* * *}(.08)$ & $-.25^{* *}(.10)$ & $-.25^{* *}(.10)$ & $-.31^{* * *}(.10)$ & $-.31^{* * *}(.10)$ \\
\hline \multicolumn{7}{|l|}{ Assessment-level measures } \\
\hline Age at assessment & $.02^{* * *}(.01)$ & $.02^{* * *}(.01)$ & $.02^{* * *}(.01)$ & $.02^{* * *}(.01)$ & $.02 * *(.01)$ & $.02^{* *}(.01)$ \\
\hline Order of assessment & $.46^{* *}(.15)$ & $.45^{* *}(.15)$ & $.43^{* *}(.17)$ & $.43^{* *}(.17)$ & $.40^{* *}(.15)$ & $.40^{* *}(.15)$ \\
\hline Wave & $-.70^{* * *}(.09)$ & $-.70^{* * *}(.09)$ & $-.82^{* * *}(.13)$ & $-.82^{* * *}(.13)$ & $-.73^{* * *}(.16)$ & $-.72^{* * *}(.16)$ \\
\hline$N$ & 5,847 & 5,847 & 5,847 & 5,847 & 5,847 & 5,847 \\
\hline Observations & 28,020 & 28,020 & 28,020 & 28,020 & 28,020 & 28,020 \\
\hline Fit statistic ${ }^{\mathrm{d}}$ & .24 & .24 & $223,591.1$ & $223,586.6$ & $221,314.8$ & $221,313.5$ \\
\hline
\end{tabular}

Notes. Two-level models account for the correlation between multiple observations from the same child. Three-level models account for the correlation between multiple observations from the same child and multiple children with the same mother. Figures in parentheses are standard errors. AFQT $=$ Armed Forces Qualifying Test.

${ }^{a}$ Reference group is intended. ${ }^{b}$ Reference group is Caucasian. ${ }^{c}$ Reference group is South. ${ }^{\mathrm{d}}$ Fit statistic is $R^{2}$ (adjusted) for ordinary least squares (OLS) models and $-2 *$ residual log-likelihood for multilevel models.

${ }^{\dagger} p<.10 .{ }^{*} p<.05 .{ }^{* *} p<.01 .{ }^{* * *} p<.001$.

Level 2 model (variation in assessments within children)

$$
\begin{aligned}
\pi_{0 i}= & \beta_{00}+\beta_{01} \times \text { unintended }+\sum \boldsymbol{\beta}_{02} \\
& \times \text { child-level controls }+\sum \boldsymbol{\beta}_{03} \\
& \times \text { family background controls }+r_{01}
\end{aligned}
$$

$$
\sum \pi_{1 i}=\sum \beta_{10}+\sum \beta_{11} \times \text { unintended }
$$

where $\beta_{00}$ is the average baseline score for all individuals over all time points, $\beta_{01}$ is the difference in the average baseline score between intended and unintended children (effect of unintended), $\boldsymbol{\beta}_{02}$ is a 
Table 5

Two-Level Models of the Change in the HOME Score After the Birth of a Younger Sibling, According to the Younger Sibling's Birth Intention Status

\begin{tabular}{|c|c|c|c|c|c|c|}
\hline & \multicolumn{2}{|c|}{ Total HOME } & \multicolumn{2}{|c|}{ Emotional support } & \multicolumn{2}{|c|}{ Cognitive support } \\
\hline & 1 & 2 & 3 & 4 & 5 & 6 \\
\hline \multicolumn{7}{|c|}{ Younger sibling's birth intention status ${ }^{a}$} \\
\hline $\begin{array}{l}\text { Unintended (unwanted } \\
\text { or mistimed) }\end{array}$ & $-12.00 *(5.23)$ & & $-11.42^{*}(6.21)$ & & $-4.97(5.64)$ & \\
\hline Unwanted & & $-.83(7.65)$ & & $-4.80(9.17)$ & & $-1.75(8.26)$ \\
\hline Mistimed & & $-17.06^{* *}(5.81)$ & & $-14.30 *(6.80)$ & & $-6.39(6.27)$ \\
\hline \multicolumn{7}{|l|}{ Child's birth intention status $^{a}$} \\
\hline $\begin{array}{l}\text { Unintended (unwanted } \\
\text { or mistimed) }\end{array}$ & $-8.86^{\dagger}(5.73)$ & & $-3.21(6.89)$ & & $-9.80^{\dagger}(6.12)$ & \\
\hline Unwanted & & $-13.48^{\dagger}(10.89)$ & & $-8.17(12.87)$ & & $-12.99(11.58)$ \\
\hline Mistimed & & $-9.09^{\dagger}(6.02)$ & & $-2.99(7.26)$ & & $-9.49^{\dagger}(6.43)$ \\
\hline \multicolumn{7}{|l|}{ Mother-/family-level measures } \\
\hline $\begin{array}{l}\text { Family income } \\
\quad \text { (in } \$ 1,000 \text { s of } 1979 \$ \text { ) }\end{array}$ & $.09 *(.05)$ & $.09 *(.05)$ & $.08^{\dagger}(.06)$ & $.08^{\dagger}(.06)$ & $.06^{\dagger}(.05)$ & $.06^{\dagger}(.01)$ \\
\hline Home ownership & $19.42^{* * *}(5.79)$ & $19.45^{* * *}(5.79)$ & $14.09 *(6.95)$ & $14.08^{*}(6.95)$ & $22.07^{* * *}(6.21)$ & $22.05^{* * *}(6.21)$ \\
\hline $\begin{array}{l}\text { Mother lives with } \\
\text { spouse/partner }\end{array}$ & $24.77^{* * *}(6.23)$ & $24.92^{* * *}(6.24)$ & $33.26^{* * *}(7.71)$ & $33.23^{* * *}(7.73)$ & $10.23^{\dagger}(6.69)$ & $10.22^{\dagger}(6.70)$ \\
\hline Mother lives with parents & $6.75(8.85)$ & $6.70(8.85)$ & $-16.48^{\dagger}(11.09)$ & $-16.57^{\dagger}(11.10)$ & $18.62 *(9.58)$ & $18.58^{*}(9.59)$ \\
\hline $\begin{array}{l}\text { Mother's total number } \\
\text { of children }\end{array}$ & $-4.23^{\dagger}(3.13)$ & $-4.44^{\dagger}(3.13)$ & $-2.52(3.85)$ & $-2.68(3.86)$ & $-3.03(3.31)$ & $-3.09(3.31)$ \\
\hline Mother's education & $11.62^{* * *}(1.48)$ & $11.68^{* * *}(1.48)$ & $5.49^{* *}(1.81)$ & $5.53^{* *}(1.81)$ & $14.24^{* * *}(1.60)$ & $14.26^{* * *}(1.60)$ \\
\hline Mother's AFQT score & $3.51^{* *}(1.40)$ & $3.61^{* *}(1.40)$ & $5.48^{* * *}(1.69)$ & $5.54^{* * *}(1.70)$ & $.95(1.49)$ & $.97(1.49)$ \\
\hline \multicolumn{7}{|l|}{ Race $^{\mathrm{b}}$} \\
\hline Latino & $-17.43^{*}(7.75)$ & $-17.12 *(7.75)$ & $-3.98(9.35)$ & $-3.86(9.36)$ & $-20.68^{* *}(8.36)$ & $-20.57^{* *}(8.36)$ \\
\hline African American & $-45.06^{* * *}(8.22)$ & $-45.19^{* * *}(8.24)$ & $-48.24^{* * *}(9.92)$ & $-48.24^{* * *}(9.95)$ & $-31.58^{* * *}(8.74)$ & $-31.55^{* * *}(8.76)$ \\
\hline \multicolumn{7}{|l|}{ Region of residence ${ }^{c}$} \\
\hline Northeast & $18.16^{* *}(7.64)$ & $17.79^{* *}(7.64)$ & $19.20 *(9.16)$ & $18.77 *(9.18)$ & $18.62^{*}(8.15)$ & $18.44^{*}(8.16)$ \\
\hline North central & $14.22 *(6.69)$ & $14.09 *(6.69)$ & $26.04^{* * *}(7.97)$ & $25.80^{* * *}(7.98)$ & $9.38^{\dagger}(7.16)$ & $9.31^{\dagger}(7.17)$ \\
\hline West & $-.83(7.27)$ & $-.70(7.27)$ & $18.67^{*}(8.80)$ & $18.68^{*}(8.80)$ & $-7.85(7.79)$ & $-7.83(7.80)$ \\
\hline \multicolumn{7}{|l|}{ Child-level measures } \\
\hline $\begin{array}{l}\text { Mother's age at focal } \\
\text { child's birth }\end{array}$ & $1.31(1.30)$ & $1.24(1.30)$ & $-.13(1.56)$ & $-.20(1.57)$ & $2.25^{\dagger}(1.38)$ & $2.23^{\dagger}(1.38)$ \\
\hline Child low birth weight & $-4.12(9.85)$ & $-4.12(9.85)$ & $1.35(11.80)$ & $1.34(11.82)$ & $-3.97(10.62)$ & $-3.95(10.63)$ \\
\hline Child's birth order & $-15.00^{* * *}(3.94)$ & $-15.19^{* * *}(3.95)$ & $-17.19^{* * *}(4.89)$ & $-17.23^{* * *}(4.91)$ & $-14.15^{* * *}(4.19)$ & $-14.15^{* * *}(4.20)$ \\
\hline Child is female & $12.69^{* *}(4.96)$ & $12.90^{* *}(4.97)$ & $6.20(5.98)$ & $6.35(5.99)$ & $13.47^{* *}(5.30)$ & $13.47^{* *}(5.31)$ \\
\hline Siblings are same sex & $3.67(4.62)$ & $3.38(4.62)$ & $5.87(5.54)$ & $5.70(5.54)$ & $-.57(4.99)$ & $-.63(4.99)$ \\
\hline $\begin{array}{l}\text { Total number of } \\
\text { assessments }\end{array}$ & $-3.80^{\dagger}(2.75)$ & $-3.89^{\dagger}(2.75)$ & $3.54(3.03)$ & $3.57(3.03)$ & $-6.95^{* *}(2.80)$ & $-6.94^{* *}(2.80)$ \\
\hline \multicolumn{7}{|l|}{ Assessment-level measures } \\
\hline Age at assessment & $.53^{* *}(.19)$ & $.50^{* *}(.19)$ & $.55^{* *}(.21)$ & $.54^{* *}(.21)$ & $.33^{*}(.19)$ & $.33^{*}(.19)$ \\
\hline Order of assessment & $-1.48(5.44)$ & $-.99(5.46)$ & $-7.63^{\dagger}(6.02)$ & $-7.47^{\dagger}(6.03)$ & $3.71(5.50)$ & $3.78(5.51)$ \\
\hline Wave & $-5.48^{*}(2.85)$ & $-5.51 *(2.86)$ & $1.65(3.35)$ & $1.70(3.35)$ & $-11.22^{* * *}(3.02)$ & $-11.20^{* * *}(3.03)$ \\
\hline $\begin{array}{l}\text { Assessment before } \\
\text { the birth }\end{array}$ & $.37^{* * *}(.02)$ & $.37^{* * *}(.02)$ & $.24^{* * *}(.02)$ & $.24^{* * *}(.02)$ & $.38^{* * *}(.02)$ & $.38^{* * *}(.02)$ \\
\hline$N$ & 2,200 & 2,200 & 2,029 & 2,029 & 2,136 & 2,136 \\
\hline Observations & 2,823 & 2,823 & 2,333 & 2,333 & 2,615 & 2,615 \\
\hline Fit statistic ${ }^{\mathrm{d}}$ & $35,073.7$ & $35,056.9$ & $29,356.7$ & $29,342.2$ & $32,665.8$ & $32,652.5$ \\
\hline
\end{tabular}

Notes. Two-level models account for the correlation between multiple observations from the same child. Figures in parentheses are standard errors. HOME $=$ Home Observation for Measurement of the Environment; AFQT = Armed Forces Qualifying Test.

${ }^{a}$ Reference group is intended. ${ }^{b}$ Reference group is Caucasian. ${ }^{\circ}$ Reference group is South. ${ }^{\mathrm{d}}$ Fit statistic is $R^{2}$ (adjusted) for ordinary least squares models and $-2^{*}$ residual log-likelihood for multilevel models. ${ }^{\dagger} p<.10 .{ }^{*} p<.05 .{ }^{* *} p<.01 .{ }^{* *} p<.001$. 
vector of differences in the average baseline score by child-level controls (effects of child-level controls), $\boldsymbol{\beta}_{03}$ is vector of differences in the average baseline score by family background controls (effects of family background controls), $r_{0 \mathrm{i}}$ is the random effect for the expected baseline score (correlation between assessments within individuals), $\boldsymbol{\beta}_{10}$ is a vector of average assessment-level controls slopes, and $\boldsymbol{\beta}_{11}$ is a vector of average assessment-level controls slope differences between intended and unintended children (interaction between unintended $\times$ Assessmentlevel controls). Note that although we include $\boldsymbol{\beta}_{11}$ in this presentation of the model, this vector of coefficients is not included in the final models presented in tables because the interaction terms were not statistically significant. (We discuss this in the Results section.)

We also compute three-level models, which account for the correlation between multiple children from the same family (or mother), in addition to the correlation between multiple observations of the same child. These models are very similar to growth curve models-our time-varying variable age is similar to time in those models. However, we hypothesize about factors in addition to time, and thus we include multiple assessment-level characteristics, as well as interactions between those characteristics and the Level 1 intercept. (This is similar to the interaction between time and the Level 1 intercept in growth curve models.) This is a withinchild-within-family fixed-effects model, and can be represented as follows, for observation $t$ for the $i$ th child of mother $j$.

Level 1 model (assessment level)

$$
y_{t i j}=\pi_{0 i j}+\sum \pi_{1 i j} \times \text { assessment-level controls }+e_{t i j}
$$

where each of these terms corresponds to a parallel term in the two-level model (above), but is also indexed for mother $j$.

Level 2 model (child level)

$$
\begin{aligned}
& \pi_{0 i j}= \beta_{00 j}+\beta_{01 j} \times \text { unintended }+\sum \boldsymbol{\beta}_{02 j} \\
& \times \text { child-level controls }+r_{0 i j} \\
& \sum \pi_{1 i j}=\sum \boldsymbol{\beta}_{10 j}+\sum \boldsymbol{\beta}_{11 j} \times \text { unintended }
\end{aligned}
$$

where, again, each of these terms corresponds to a parallel term in the two-level model (above), but is also indexed for mother $j$. For example, $\beta_{00}$ is now the average baseline score within mother/family $j$, and $\boldsymbol{\beta}_{11 j}$ is a vector of average assessment-level controls slope differences in mother/family $j$ by child-level controls (the interactions between unintended $\times$ assessment-level controls).
Level 3 model (family level)

$$
\begin{gathered}
\beta_{00 j}=\gamma_{000}+\gamma_{001} \times \text { mother } / \text { family-level controls }+u_{00 j} \\
\beta_{01 j}=\gamma_{010}+\gamma_{011} \times \text { mother } / \text { family-level controls } \\
\sum \boldsymbol{\beta}_{02 j}=\sum \gamma_{020} \\
\sum \boldsymbol{\beta}_{10 j}=\sum \gamma_{100} \\
\sum \boldsymbol{\beta}_{11 j}=\sum \gamma_{110}
\end{gathered}
$$

where $\gamma_{000}$ is the overall average score, $\gamma_{001}$ is the difference in the overall average score by mother/family-level controls, $u_{00 j}$ is the random effect for the expected baseline score (correlation between children within family $j$ ), $\gamma_{010}$ is vector of average unintended slopes, $\gamma_{011}$ is vector of differences in the average unintended slope differences by mother/family-level controls, $\gamma_{020}$ is vector of average child-level controls slopes, and $\gamma_{100}$ is vector of average slopes for assessment-level controls.

Intention status of a sibling's birth and change in resources. We use crosslag regression models to assess the change in HOME scores after a younger sibling's birth. In this method, the score of the dependent variable after the birth is regressed on the score of the dependent variable before the birth plus the intention status of the birth as well as the other independent variables. Because our central focus is on the process of change in the home environment and parental resources, we use crosslag (or lagged dependent variable) regression models. These models allow us to assess change in the dependent variables after the birth of a younger sibling, while also including time-invariant indicators of the situation before the sibling birth as controls.

Note that Johnson (2005) advocates for a change score model, particularly when there is measurement error in the independent variables, or when important exogenous predictors of the outcome are unobserved (omitted variables). However, the cross-lag model more closely fits our hypotheses, because a time-invariant variable (intention status) is our key predictor of interest, and because we hypothesize about several prebirth family and child characteristics. In addition, as Johnson's simulation demonstrates, the crosslag model is estimated correctly, even in the face of substantial measurement error in the independent variables, as long as exogenous predictors (selection factors and stable individual characteristics) are well controlled. Because the NLSY data were specifically designed 
to investigate child development, including the quality of the home environment, an extensive set of variables to account for the selection into unintended childbearing are included in the data set and in our models. In addition, if we instead implemented our independent variables as change scores (between the pre- and postbirth waves), this would necessarily include some change occurring after the birth of the sibling, which would be mediators in our model rather than exogenous controls. This overcontrolled model would result in an underestimate of the relationship between intention status and change in parental resources.

To be included in each model, an existing child must have a younger sibling and valid HOME scores must be available from both before and after the sibling's birth. If a measure of any of the independent variables was not available from the interview directly preceding the sibling's birth, it was taken from the interview prior to the prebirth interview. (In the worst case, family income, the measure is taken from the interview prior to the prebirth interview in approximately $10 \%$ of cases. For mother's education, e.g., it is only taken from the interview prior to the prebirth interview in $4 \%$ of cases.) In addition, because births are clustered within mothers in the data, we estimate two-level models.

The model is as follows for the $i$ th child of mother $j$ :

Level 1 model (birth/child level)

$$
\begin{aligned}
y_{i j}= & \pi_{0 j}+\pi_{1 j} \times \text { prebirth score }+\pi_{2 j} \times \text { unintended } \\
& +\pi_{3 j} \times \text { prebirth score } \times \text { unintended } \\
& +\sum \pi_{4 j} \times \text { birth } / \text { child-level controls }+e_{t i j}
\end{aligned}
$$

where $y_{i j}$ is the focal child's score after the birth of sibling $i$ to mother $j, \pi_{0 j}$ is the focal child's expected baseline score after sibling ij's birth, $\pi_{1 j}$ is the slope for the focal child's score before his or her sibling's birth, $\pi_{2 j}$ is the difference in the expected baseline score between intended and unintended sibling births (effect of unintended), $\pi_{3 j}$ is the slope representing the interaction between intention status and focal child's prebirth score, $\Sigma \pi_{4 j}$ is a vector of slopes for birth/child-level controls, and $e_{t i j}$ is the random error for sibling birth $i j$.

Level 2 model (mother level)

$$
\begin{gathered}
\pi_{0 j}=\beta_{00}+\sum \boldsymbol{\beta}_{01} \times \text { mother } / \text { family-level controls }+r_{0 j} \\
\pi_{1 j}=\beta_{10} \\
\pi_{2 j}=\beta_{20}+\sum \boldsymbol{\beta}_{21} \times \text { mother } / \text { family-level controls }
\end{gathered}
$$

$$
\begin{aligned}
\pi_{3 j} & =\beta_{30} \\
\sum \boldsymbol{\pi}_{4 j} & =\sum \boldsymbol{\beta}_{40}
\end{aligned}
$$

where $\beta_{00}$ is the overall average score after the sibling's birth, $\Sigma \boldsymbol{\beta}_{01}$ is a vector of differences in the overall average score by mother/family-level controls, $r_{01}$ is the random effect for the expected baseline score (the correlation between individuals within the same mother/family), $\beta_{10}$ is the slope for prebirth score, $\beta_{20}$ is the difference in the overall average score between intended and unintended births (effect of unintended), $\Sigma \boldsymbol{\beta}_{21}$ is a vector of unintended versus intended slope differences by mother/family-level controls (interactions between unintended and mother/family-level controls), $\beta_{30}$ is the slope for the prebirth score $\times$ unintended interaction term, and $\Sigma \boldsymbol{\beta}_{40}$ is a vector of birth/child-level controls slope differences. Note that there are many other possible random effects terms, which represent the extent to which each variable or set of variables influences the correlation between births within a family. We only include the random intercept terms because that most closely matches our theoretical framework and specific hypotheses.

\section{Results}

Children's Birth Intention Status and HOME and Parenting Resources

Tables 2-4 present the OLS, two-level (observations nested within individuals), and three-level (observations nested within individuals nested within mothers) models of the relation between the intention status of the focal child's own birth and his/her total HOME score, cognitive support subscore, and emotional support subscore. Recall that, in these models, each observation for each child in the data set (who has a valid HOME score) is included in the analysis. Intention status of the focal child's birth is the key independent variable.

The results in Tables $2-4$ demonstrate a statistically significant and consistent relation between the intention status of a child's birth and his/her HOME score. In all three types of models (OLS, two-level, and three-level), children born from unintended pregnancies (either mistimed or unwanted) scored lower on their age-appropriate HOME measure than children from intended births. Consistent effects are also evident for both the cognitive and emotional support subscales. This pattern of results suggests that children born as a result of an unintended pregnancy have access to 
fewer family resources than children who were intended at conception.

The OLS models in Table 2 demonstrate that the HOME scores assigned to children whose births were unintended are 1.29 points lower, on average, than the HOME scores assigned to children whose births were intended (1.96 points for unwanted births and 1.09 points for mistimed births). Of course, these are relatively small effects when compared with the standard deviation of the overall HOME score and its subscores-approximately $6 \%-12 \%$ of 1 SD. However, these effect sizes are similar to the magnitude of other important social effects on parenting resources, such as a 2-point difference in mother's AFQT score, or a 1- or 2-year difference in mother's education level, or an 18-year difference in mother's age at child's birth.

The two-level models in Table 2 show that the average HOME score for unintended children is 1.62 points lower than the average HOME score for intended children. Similarly, average HOME scores assigned to children of both unwanted and mistimed births are lower than those assigned to children of intended births (2.42 points for unwanted births and 1.37 points for mistimed births). Note that these are slightly larger coefficients than the corresponding OLS coefficients. Recall that these models are similar to the OLS models in Joyce et al. (2000a, 2000b), who found a significant relation between birth intention status on the one hand, and maternal behavior and child development on the other. These results are consistent with those models, although we focus on a different dependent variable. They are not, however, consistent with Baydar's (1995) findings, where the bivariate association between intention status and resources was explained almost entirely by additional control variables.

The three-level fixed-effects (within-child-withinmother) models shown in Table 2 account for the nested structure of multiple observations per child as well as multiple children per mother. These results also indicate that children whose births were unintended generally had less access to parental resources than their siblings whose births were intended. Unintended children scored .49 points lower on the HOME scale than their intended siblings-unwanted children scored .95 points lower, and mistimed children scored .37 points lower. Although these effects are not substantively as large as, for example, the relation between home ownership and the quality of the home environment, they are similar in magnitude to other important effects, such as a mother having an additional child, or the child being born with low birth weight. In addition, the pattern of results is strong.

Tables 3 and 4 estimate models parallel to those in Table 2, but for the emotional support subscale of the HOME measure (Table 3) and for the cognitive support subscale of the HOME measure (Table 4). These models demonstrate that the relation between intention status and resources is similar for the total HOME score and the emotional and cognitive subscores. The intention status differential is larger for the emotional subscore than the cognitive subscore. Note that the difference in cognitive support between mistimed and intended births is not statistically significant.

Note also that the mother-/family-level, childlevel, and assessment-level measures have interesting and important relations with parental resources. Families with higher income, home ownership, two parents, fewer children, and more educated and older mothers have more emotional and cognitive parental resources. Latino families and African American families seem to be less able to provide cognitive supports to children, and African American families are also less able to provide emotional resources. Families in the Northeast and North Central regions of the country provide more parental resources than families in the South. In addition, characteristics of the children affect the parental distribution of resources-children who are high parity, low birth weight, and male receive fewer cognitive and emotional resources. And, several characteristics of the assessments themselves affect the scores-older children and later assessments score higher, and later waves of the study produce lower cognitive scores. It is also important to note, however, that we did not find differences in the unintended versus intended differential that varied by any of these mother-/family-level, child-level, and assessment-level measures. In other words, we did not find interaction effects between these measures and the intention status of the child.

Throughout Tables 2-4, the vast majority of the coefficients in the three-level fixed-effects models are smaller than the corresponding coefficients in the OLS or two-level models. This is because these models focus on differences between children within the same family, comparing siblings of different intention status but who share the same family-level characteristics. Thus, these models demonstrate that the difference in HOME scores between unintended and intended siblings within the same families is smaller than the overall difference in HOME scores between unintended and intended children. These results suggest two 
possible conclusions. First, the three-level models may more adequately control for unobserved family-level factors that produce the apparent relation (in the two-level and OLS models) between intention status of the child's birth and his/her subsequent home environment. A second interpretation of the smaller differentials is that unintended births affect the resources available to all of the children within a family (i.e., not just to the unintended child); thus the scores for intended children in such families are relatively lower than for all intended children and relatively less differentiated from the scores of their unintended siblings. The analyses below explore this possibility in greater detail.

\section{Birth Intention Status of a Younger Sibling and Change in Resources}

Table 5 shows the results of the change in HOME scores after the birth of a younger sibling, according to the younger sibling's intention status. Models 1 and 2 show models of the total HOME score, Models 3 and 4 show models of the emotional subscale, and Models 5 and 6 show models of the cognitive subscale. The models provide evidence for a relationship between the intention status of a younger child's birth and change in the HOME score between the wave prior to the birth and the wave subsequent to the birth. Model 1 suggests that having an unintended versus an intended younger sibling is associated with a larger average decline in the older child's total HOME score. Model 2 disaggregates unintended births into unwanted and mistimed births, and demonstrates that the effect is limited to having a mistimed younger sibling, but not an unwanted younger sibling.

Model 4 shows that the birth of a mistimed younger sibling is associated with significantly greater declines in emotional support than the birth of an intended younger sibling. Models 5 and 6 show that the intention status of the younger sibling's birth is not associated with changes in cognitive support. Note in Model 4 that the magnitude of the emotional support coefficient for mistimed younger siblings is nearly 3 times as large as the coefficient for unwanted younger siblings $(-14.30$ vs. -4.80$)$. Although not a statistically significant difference (due to the relatively large standard errors of the estimates), this suggests that perhaps mistimed younger siblings cause larger declines in the quality of the home environment, whereas unwanted siblings do not cause these declines. Although being born oneself from either a mistimed or unwanted pregnancy is associated with differences in parental resources relative to children born from intended pregnancies, it appears that only mistimed sibling births affect resources available to existing children within a family. This suggests that fertility timing failures are more difficult for parents in terms of maintaining emotional resource availability, in particular, but fertility number failures are not as difficult.

Note also that the magnitude of the coefficient for whether the younger sibling was mistimed is similar in magnitude to other important influences on parental resources-whether the family owns or rents its home, one half the size of whether the mother lives with a spouse or partner, a roughly 3-year difference in education, a 2.6-point difference in AFQT score, or a one-unit increase in birth order.

Note also that the mother-/family-level, childlevel, and assessment-level measures have interesting and important relations with change in parental resource availability after a birth. Families who own their homes, include two parents, have more highly educated and higher AFQT scoring mothers experience more positive growth in parental resources. Home ownership and mother's education are more strongly related to growth in cognitive resources, while having two parents in the home and AFQT scores are more strongly related to growth in emotional support. Latino and African American families experience less growth in parental resources after a birth, and those who live in the Northeast or North Central regions experience greater growth in parental resources. In addition, characteristics of the children affect change in parental resources after a birth-children who are high parity experience larger decreases in emotional support, and male children experience larger decreases in cognitive support. Families with more assessments experience slightly more negative change in cognitive resources after a birth. Also, several characteristics of the assessments themselves affect change in resourcesolder children experience less negative change in cognitive support, and net of age, the change in emotional resources is more negative for later assessments. Later waves of the study show more negative change in cognitive assessment scores, on average. These results pertaining to the change in parental resources are, for the most part, consistent with overall effects on baseline levels of parental resources, as well. In other words, families who are better able to provide resources to their children also experience more growth in those resources over time. It is also important to note that we did not find differences in the unintended versus intended differential that varied by any of these mother-/family-level, child-level, and assessment-level measures. In other words, we 
Table 6

Two-Level Models of the Change in Interviewer-Assessed Safety and Appearance of the Home After the Birth of a Younger Sibling, According to the Younger Sibling's Birth Intention Status

\begin{tabular}{|c|c|c|c|c|}
\hline & \multicolumn{2}{|l|}{1} & \multicolumn{2}{|l|}{2} \\
\hline \multicolumn{5}{|c|}{ Younger sibling's birth intention status ${ }^{a}$} \\
\hline $\begin{array}{l}\text { Unintended (unwanted } \\
\text { or mistimed) }\end{array}$ & $-.02^{* *}$ & $(.01)$ & & \\
\hline Unwanted & & & $-.03^{* *}$ & $(.01)$ \\
\hline Mistimed & & & $-.02^{*}$ & $(.01)$ \\
\hline \multicolumn{5}{|l|}{ Child's birth intention status $^{\mathrm{a}}$} \\
\hline $\begin{array}{l}\text { Unintended (unwanted } \\
\text { or mistimed) }\end{array}$ & .003 & $(.01)$ & & \\
\hline Unwanted & & & .01 & $(.02)$ \\
\hline Mistimed & & & .002 & $(.01)$ \\
\hline \multicolumn{5}{|l|}{ Mother-/family-level measures } \\
\hline $\begin{array}{l}\text { Family income } \\
\text { (in } \$ 1,000 \text { s of } 1979 \$ \text { ) }\end{array}$ & -.0001 & $(.0001)$ & -.0001 & $(.0001)$ \\
\hline Home ownership & $.02^{* *}$ & $(.01)$ & $.02^{* *}$ & $(.01)$ \\
\hline $\begin{array}{l}\text { Mother lives with } \\
\text { spouse/partner }\end{array}$ & -.004 & $(.01)$ & -.004 & $(.01)$ \\
\hline Mother lives with parents & .01 & $(.02)$ & .01 & $(.02)$ \\
\hline $\begin{array}{l}\text { Mother's total number } \\
\text { of children }\end{array}$ & $-.03^{* * *}$ & $*(.01)$ & $-.03^{* * *}$ & $(.01)$ \\
\hline Mother's education & $.01^{* * *}$ & $*(.003)$ & $.01^{* * *}$ & $(.003)$ \\
\hline Mother's AFQT score & $-.005^{*}$ & $(.002)$ & $-.005^{*}$ & $(.002)$ \\
\hline \multicolumn{5}{|l|}{ Race $^{\mathrm{b}}$} \\
\hline Latino & $.02^{*}$ & $(.01)$ & $.02^{*}$ & $(.01)$ \\
\hline African American & $-.02^{\dagger}$ & $(.01)$ & $-.02^{\dagger}$ & $(.01)$ \\
\hline \multicolumn{5}{|l|}{ Region of residence $^{c}$} \\
\hline Northeast & -.002 & $(.01)$ & -.002 & $(.01)$ \\
\hline North central & -.01 & $(.01)$ & -.01 & $(.01)$ \\
\hline West & $-.04^{* * *}$ & $*(.01)$ & $-.04^{* * *}$ & $(.01)$ \\
\hline \multicolumn{5}{|l|}{ Child-level measures } \\
\hline $\begin{array}{l}\text { Mother's age at focal } \\
\text { child's birth }\end{array}$ & $.004^{\dagger}$ & $(.002)$ & $.004^{*}$ & $(.002)$ \\
\hline Child low birth weight & .02 & $(.02)$ & .02 & $(.02)$ \\
\hline Child's birth order & .01 & $(.01)$ & .01 & $(.01)$ \\
\hline Child is female & -.01 & $(.01)$ & -.01 & $(.01)$ \\
\hline $\begin{array}{l}\text { Total number of } \\
\text { assessments }\end{array}$ & .003 & $(.005)$ & .003 & $(.005)$ \\
\hline Siblings are same gender & -.004 & $(.01)$ & -.004 & $(.01)$ \\
\hline \multicolumn{5}{|l|}{ Assessment-level measures } \\
\hline Age at assessment & -.0001 & $(.001)$ & -.00003 & $3(.001)$ \\
\hline Order of assessment & -.01 & $(.01)$ & -.01 & $(.01)$ \\
\hline Wave & $-.01^{*}$ & $(.005)$ & $-.01^{*}$ & $(.005)$ \\
\hline $\begin{array}{l}\text { Assessment before } \\
\text { the birth }\end{array}$ & $.21^{* * *}$ & $*(.02)$ & $.21^{* * *}$ & $(.02)$ \\
\hline$N$ & 2,175 & & 2,175 & \\
\hline Observations & 2,759 & & 2,759 & \\
\hline Fit statistic ${ }^{\mathrm{d}}$ & 242.4 & & 231.0 & \\
\hline
\end{tabular}

Notes. Two-level models account for the correlation between multiple observations from the same child. Figures in parentheses are standard errors. AFQT $=$ Armed Forces Qualifying Test.

${ }^{a}$ Reference group is intended. ${ }^{b}$ Reference group is Caucasian. ${ }^{\mathrm{c}}$ Reference group is South. ${ }^{\mathrm{d}}$ Fit statistic is $R^{2}$ (adjusted) for ordinary least squares (OLS) models and $-2^{*}$ residual loglikelihood for multilevel models.

${ }^{\dagger} p<.10 .{ }^{*} p<.05 .{ }^{* *} p<.01 .{ }^{* * *} p<.001$ did not find interaction effects between these measures and the intention status of the child.

It is possible that mothers who evaluated a recent birth as unintended describe their home environment more negatively than mothers who evaluated their recent birth as intended, regardless of the true quality of the home environment. Table 6 illustrates the change in interviewer reports of home safety and appearance- $a$ subset of the HOME inventory items-after the birth of a younger sibling. Interviewers' perceptions of the safety and appearance of the environment declined more for mothers whose recent birth was unintended than for mothers whose recent birth was intended (coefficient $=-.02$, $p<.01$ ). When unintended births are disaggregated into unwanted and mistimed births, both mistimed and unwanted births are significantly related to the decline in home safety and appearance. This suggests that mothers with a recent unintended birth are less able to maintain the safety of their children's environment, provide a light or perceptually interesting environment, and keep a clean and uncluttered home. Although the majority of mothers with a recent birth may have at least temporary difficulty with these tasks, it appears that mothers with recent unintended births are less able to do so than mothers with recent intended births.

Recall that this difference is net of a host of other family-level factors that might influence home safety and appearance-family income, number of children in the household, owned versus rented housing, number of parents in the household, and mother's education. These results bolster our interpretation that the home environment declines more for families with unintended births than for families with intended births, and this is not likely an artifact of a tendency for mothers who characterize recent births as unintended to have more negative perceptions of their home environment.

\section{Discussion}

This study investigated the differential and changing availability of family resources to children based on their own birth intention status and that of younger siblings. Results were based on a large national cohort of families representing a broad socioeconomic spectrum, and a host of important family background characteristics that might be linked with family resource availability were controlled in all analyses. Results indicate that children born from unintended pregnancies had fewer family resources than children born from intended 
pregnancies, in terms of both emotional and cognitive resources, and as rated by both mothers and interviewers. This is consistent with earlier studies demonstrating that unintended childbearing is associated with a host of negative health statuses for children and their mothers, ranging from infant health problems and infant mortality, to maternal depression, low self-esteem, problematic parent-child relationships, and even child abuse (Axinn et al., 1998; Barber et al., 1999; Baydar, 1995; Brown \& Eisenberg, 1995; Joyce et al., 2000a; Kost, Landry, \& Darroch, 1998; Najman, Morrison, Williams, Andersen, \& Keeping, 1991; Salmon \& Drew, 1992; Zuravin, 1991).

To investigate whether these relations are due mainly to unobserved family-level heterogeneity, we estimated fixed-effects (within-mother) models that account for multiple observations per individual and compare siblings of different intention statuses within the same family. These models suggest that the overall differences between all unintended and intended children are in part due to family-level differences, but that key differences remain between unintended and intended children, even within the same family. We interpret the decrease in relative size between OLS and fixedeffects (within-mother) models to suggest that all of the children in a family may be affected by an unintended birth, not just the child born from the unintended birth. Further bolstering this interpretation, additional models demonstrate that the availability of home resources (both cognitive and emotional) changes after the birth of a sibling, with larger decreases after the birth of an unintended sibling relative to an intended sibling. Finally, models using interviewer observations of the home environment suggest that these relations may indicate true declines in home resources rather than capturing mothers' biased perceptions of fewer home resources after the birth of an unintended child.

Being born oneself from an unwanted pregnancy appears to be more strongly related to the receipt of parental resources than being born from a mistimed pregnancy, but the birth of a mistimed younger sibling is more strongly related to parental resources than the birth of an unwanted younger sibling. This pattern may emerge because parents' stress and lack of patience may be directed explicitly toward an unwanted child himself or herself, but a mistimed birth may exacerbate stress mainly in interactions with other children. In general, mistimed children may extract a greater tax on parental resources for the entire family because, although they wanted another child, they simply had less time than they expected to prepare for that child. In contrast, the consequences of unwanted births may be directed more toward the child himself or herself. Mistimed and unwanted births are qualitatively different, perhaps especially because mistimed births occur more frequently to young women, while unwanted births tend to occur more frequently to women who are near the end of their reproductive years. Of course, these types of births have many commonalities, as well, and the extent to which their causes and consequences differ in varying circumstances is an empirical question for further research.

Across the multiple analyses in this article, the consequences of unintended childbearing appear stronger in terms of emotional resources than in terms of cognitive resources. Previous studies have documented that unwanted children are more likely to receive critical, punitive parenting-and even abusive and neglectful parenting - than other children (Barber et al., 1999; Zuravin, 1991). Results of the current study suggest, however, that unintended children, particularly those born from unwanted pregnancies, receive harsher parenting relative to an intended sibling. Inequitable parental treatment is known to have significant long-term negative effects on the adjustment and self-esteem of the slighted child (McGuire, Dunn, \& Plomin, 1995; Volling \& Elins, 1998). It is certainly plausible that parents' tendency to treat unwanted children more harshly in general, as well as parents' tendency to be differentially more harsh in parenting their unwanted children relative to their intended children, contribute to the poor adjustment outcomes of unwanted children (cf. Boyle et al., 2004). Unwanted children experience disproportionately high rates of school failure, behavior problems, and low self-esteem (Axinn et al., 1998; Brown \& Eisenberg, 1995; Myhrman, Olsen, Rantakallio, \& Laara, 1995). Understanding how these within- and between-family effects contribute specifically to unwanted children's adjustment difficulties is an important area for further study.

Several factors should be considered when interpreting these findings. First, other factors co-occurring with unintended childbearing that were not controlled in the current analyses may have contributed to the associations found. Mothers' knowledge of their circumstances, or expectations of their future circumstances, may influence whether they evaluate their pregnancies as intended or unintended. For example, unintended childbearing often co-occurs with postpartum maternal depression, parents' marital conflict, and marital dissolution (Barber et al., 1999; Jekielek, 1998; Najman 
et al., 1991). Regardless of whether maternal depression or marital conflict leads to or results from unintended childbearing, these factors likely affect all children within a family and may have extraneously contributed to the effects found in the current study. In addition, unintended pregnancy has been associated with women's lower quality prenatal health care and to poorer prenatal and postpartum health behaviors such as smoking and drinking (Brown \& Eisenberg, 1995; Hellerstedt et al., 1998; Kost et al., 1998). These behaviors may contribute to children's health or behavioral problems, which in turn could lead to parents' lack of resource investment (spend less time with children, treat children more harshly). These and similar processes should be considered when interpreting study findings. It should also be acknowledged that women's intentions to become pregnant and their reports of the "intendedness" of their children often involve conflicting and strongly socially proscribed feelings, and may not be easily dichotomized as intended or unintended as analyzed within the current study (Bachrach \& Newcomer, 1999; Rosenzweig \& Wolpin, 1993). Finally, fathers' reports of their children's intention status may differ from mothers' reports, and should be considered as well (Korenman, Kaestner, \& Joyce, 2002).

These caveats aside, our study results underscore the important role played by children's birth intention status in the distribution of parenting resources to children within a family. Collectively, these findings suggest broader consequences in terms of the availability of parental resources as a function of pregnancy intentions than has previously been demonstrated. Furthermore, parents' differential investment in their children may begin earlier than previously demonstrated, even as early as conception. A within-family systems approach, which emphasizes the dynamic and interconnected relationships of individuals within a family, is necessary to fully embrace and understand these mercurial family-level shifts (Cox \& Paley, 1997; Sameroff \& Mackenzie, 2003). Important next steps would be to further explore the within- and between-familylevel effects associated with unintended childbearing. For example: are these consequences relatively short-lived, or do they persist over the long term? Do successively fewer developmental resources become available after progressively more unintended children are born within a family? Can a family recover from an unintended child's birth by having subsequent children who are intended? Although we have fully exploited the rich longitudinal data in the NLSY, the size of the 2004 sample of children, coupled with the relative rarity of unintended childbearing, prevents us from exploring these duration-related questions. Such questions represent interesting lines for further inquiry, and important priorities for researchers interested in the consequences of unintended childbearing.

\section{References}

Axinn, W. G., Barber, J. S., \& Thornton, A. (1998). The long-term impact of childbearing decisions on children's self-esteem. Demography, 35, 435-444.

Bachrach, C., \& Newcomer, S. (1999). Intended pregnancies and unintended pregnancies: Distinct categories or opposite ends of a continuum? Family Planning Perspectives, 31, 251-252.

Barber, J. S., Axinn, W. G., \& Thornton, A. (1999). Unwanted childbearing, health, and mother-child relationships. Journal of Health and Social Behavior, 40, 231-257.

Baydar, N. (1995). Consequences for children of their birth planning status. Family Planning Perspectives, 27, 228-234.

Baydar, N., Greek, A., \& Brooks-Gunn, J. (1997). A longitudinal study of the effects of the birth of a sibling during the first 6 years of life. Journal of Marriage and Family, 59, 939-956.

Baydar, N., Hyle, P., \& Brooks-Gunn, J. (1997). A longitudinal study of the effects of the birth of a sibling during preschool and early grade school years. Journal of Marriage and Family, 59, 957-965.

Becker, G. S., \& Thomes, N. (1986). Human capital and the rise and fall of families. Journal of Labor Economics, 4, S1-S139.

Behrman, J. R.. (1997). Intrahousehold distribution and the family. In M. R. Rosenzweig \& O. Stark (Eds.), Handbook of population and family economics (pp. 125187). New York: Elsevier Science.

Behrman, J., Pollak, R. A., \& Taubman, P. (1986). Do parents favor boys? International Economic Review, 27, 31-52.

Behrman, J., Pollak, R. A., \& Taubman, P. (1995). Parental preferences and provision or progeny. In J. Behrman, R. A. Pollak, \& P. Taubman (Eds.), From parent to child: Intrahousehold allocations and intergenerational relations in the United States (pp. 23-42). Chicago: University of Chicago Press.

Blake, J. (1987). Differential parental investment: Its effects on child quality and status attainment. In J. B. Lancaster, J. Altmann, A. S. Rossi, \& L. R. Sherrod (Eds.), Parenting across the life span: Biosocial dimensions (pp. 351-375). New York: Aldine De Gruyter.

Boyle, M. H., Jenkins, J. M., Georgiades, K., Cairney, J., Duku, E., \& Racine, Y. (2004). Differential-maternal parenting behavior: Estimating within- and between-family effects on children. Child Development, 75, 1457-1476.

Bradley, R., \& Corwyn, R. (2005). Caring for children around the world: A view from HOME. International Journal of Behavioral Development, 29, 468-478. 
Bradley, R., Corwyn, R., Burchinal, M., Pipes McAdoo, H., \& Garcia Coll, C. (2001a). The home environments of children in the Unites States Part I: Variations by age, ethnicity, and poverty status. Child Development, 72, 1844-1867.

Bradley, R., Corwyn, R., Burchinal, M., Pipes McAdoo, H., \& Garcia Coll, C. (2001b). The home environments of children in the Unites States Part II: Relations with behavioral development through age 13. Child Development, 72, 1868-1886.

Brown S. S., \& Eisenberg L. (Eds.) (1995). The best intentions: Unintended pregnancy and the well-being of children and families. Washington, DC: National Academy Press.

Caldwell, B. M., \& Bradley, R. H. (1984). Home Observation for Measurement of the Environment. Little Rock: Center for Child Development and Education, University of Arkansas.

Chandra, A., Martinez, G. M., Mosher, W. D., Abma, J. C., \& Jones, J. (2005). Fertility, family planning, and reproductive health of U.S. women: Data from the 2002 National Survey of Family Growth. Vital Health Statistics, 23, 1-160.

Conley, D. (2000). Sibship sex composition: Effects on educational attainment. Social Science Research, 29, 441-457.

Conley, D. (2004). The pecking order: Which siblings succeed and why. New York: Pantheon.

Cox, M. J., \& Paley, B. (1997). Families as systems. Annual Review of Psychology, 48, 243-267.

Draper, P., \& Harpending, H. (1987). Parent investment and the child's environment. In J. B. Lancaster, J. Altmann, A. S. Rossi, \& L. R. Sherrod (Eds.), Parenting across the life span: Biosocial dimensions (pp. 207-235). New York: Aldine De Gruyter.

Foster, E. M. (2002). How economists think about family resources and child development. Child Development, 73, 1904-1914.

Geronimus, A. T., \& Korenman, S. (1992). The socioeconomic consequences of teen childbearing reconsidered. Quarterly Journal of Economics, 107, 1187-1214.

Hellerstedt, W. L., Pirie, P. L., Lando, H. A., Curry, S. J., McBride, C. M., Grothaus, L. C., et al. (1998). Differences in preconceptional and prenatal behaviors in women with intended and unintended pregnancies. American Journal of Public Health, 88, 663-666.

Henshaw, S. K. (1998). Unintended pregnancy in the United States. Family Planning Perspectives, 30, 24-29, 46.

Jekielek, S. M. (1998). Parental conflict, marital disruption and children's emotional well-being. Social Forces, 76, 905-935.

Johnson, D. (2005). Two-wave panel analysis: Comparing statistical methods for studying the effects of transitions. Journal of Marriage and Family, 67, 1061-1075.

Joyce, T., Kaestner, R., \& Korenman, S. (2000a). The effect of pregnancy intention on child development. Demography, 37, 83-94.

Joyce, T., Kaestner, R., \& Korenman, S. (2000b). The stability of pregnancy intentions and pregnancy-related maternal behaviors. Maternal and Child Health Journal, 4, 171-178.
Korenman, S., Kaestner, R., \& Joyce, T. (2002). Consequences for infants of parental disagreement in pregnancy intention. Perspectives on Sexual and Reproductive Health, 34, 198-205.

Kost, K., Landry, D. J., \& Darroch, J. E. (1998). The effects of pregnancy planning status on birth outcomes and infant care. Family Planning Perspectives, 30, 223-230.

Mayer, S. E. (1997). What money can't buy: Family income and children's life chances. Cambridge, MA: Harvard University Press.

McGarry, K., \& Schoeni, R. F. (1995). Transfer behavior: Measured for the redistribution of resources within the family. Journal of Human Resources, 30, 375-391.

McGuire, S., Dunn, J., \& Plomin, R. (1995). Maternal differential treatment of siblings and children's behavioral problems: A longitudinal study. Development and Psychopathology, 7, 515-528.

Myhrman, A., Olsen, P., Rantakallio, P., \& Laara, E. (1995). Does the wantedness of a pregnancy predict a child's educational attainment? Family Planning Perspectives, 27, 116-119.

Najman, J. M., Morrison, J., Williams, G., Andersen, M., \& Keeping, J. D. (1991). The mental health of women six months after they give birth to an unwanted baby: A longitudinal study. Social Science and Medicine, 32, 241-247.

Pitt, M. M., Rosenzweig, M. R., \& Hassan, N. (1990). Productivity, health and inequality in the intrahousehold distribution of food in low-income countries. American Economic Review, 824, 1139-1156.

Rosenzweig, M. R. (1986). Birth spacing and sibling inequality: Asymmetric information within the household. International Economics Review, 27, 55-76.

Rosenzweig, M. R., \& Wolpin, K. I. (1993). Maternal expectation and ex-post rationalizations: The usefulness of survey information on the wantedness of children. Journal of Human Resources, 28, 206-229.

Salmon, P., \& Drew, N. C. (1992). Multidimensional assessment of women's experience of childbirth: Relationship to obstetric procedure, antenatal preparation and obstetric history. Journal of Psychosomatic Research, 36, 317-327.

Sameroff, A., \& Mackenzie, M. (2003). Research strategies for capturing transactional models of development: The limits of the possible. Development and Psychopathology, 15, 613-640.

Sandberg, J. F., \& Hofferth, S. L. (2001). Changes in children's time with parents, U.S. 1981-1997. Demography, 38, 423-436.

Thomas, D. (1990). Intra-household resource allocation: An inferential approach. Journal of Human Resources, 25, 635-664.

Volling, B. L., \& Elins, J. L. (1998). Family relationships and children's emotional adjustment as correlates of maternal and paternal differential treatment: A replication with toddler and preschool siblings. Child Development, 69, 1640-1656.

Zuravin, S. J. (1991). Unplanned childbearing and family size: Their relationship to child neglect and abuse. Family Planning Perspectives, 23, 155-161. 